\title{
Noches de adrenalina de Carmen Ollé como poesía integral neovanguardista*
}

\author{
Carmen Ollé's Noches de adrenalina as neo-avant-garde integral poetry
}

\section{Giovanna Iubini Vidal}

Universidad Austral de Chile, Instituto de Lingüística y Literatura, Valdivia, Chile.

Correo electrónico: giovanna.yubini@docentes.uach.cl

Este artículo se propone analizar el poemario de Carmen Ollé, Noches de adrenalina, desde la perspectiva de la poesía integral, es decir, desde la estética del grupo peruano Hora Zero. Esta interpretación enfatiza en los aspectos neovanguardistas del texto, especialmente, en el proyecto hipervitalista de la relación entre el arte, la vida y la política, así como en la metarreflexión e intertextualidad.

Palabras clave: neovanguardia, Hora Zero, poesía integral, manifiestos, hipervitalismo

This paper intends to analyze Carmen Ollé's poetry book, Noches de adrenalina (Nights of Adrenaline), from the perspective of integral poetry, that is, from the aesthetic of the Peruvian group Zero Hour. This understanding emphasizes on the neo- avant-garde aspects of the text, particularly in the hipervitalist project emerging from the relationship between art, life, and politics, as well as the meta-reflection and the intertextuality.

Key words: neo-avant-garde, Zero Hour, integral poetry, manifesto, hipervitalism

\section{INTRODUCCIÓN}

Decía Octavio Paz (1990) que la poesía moderna se funda como una tradición de ruptura donde el afán por la búsqueda de lo nuevo constituiría su sello particular, pero sólo en el caso de que la novedad sea de carácter desacralizador, es decir, debe constituir "negación del pasado y afirmación de ser algo distinto" (1990: 20). Leída con estos parámetros, la poesía hispanoamericana constantemente se debate en la dialéctica "tradición y ruptura". En este sentido, el repertorio literario que comienza a surgir a partir de los años 50 en el Cono Sur es particularmente desafiante de

\footnotetext{
Este artículo forma parte del proyecto FONDECYT 1100446 "Neovanguardias de la poesía hispanoamericana (1960-1980): Heterogeneidades, mutaciones, migraciones" del que soy colaboradora. El investigador responsable es el Dr. Oscar Galindo.
} 
las convenciones literarias, mostrando como sistema de preferencias una poesía conversacional, irónica y desacralizadora, de clara influencia anglosajona.

A partir de los últimos años de la década del 50, distintos grupos y movimientos a lo largo de Hispanoamérica retornaron a las claves estéticas de la vanguardia y propusieron profundas transformaciones, hibridando el discurso textual con referencias múltiples y heterogéneas, e incorporando los discursos de la ciencia, la religión, la filosofía, la lógica, la política, así como los discursos étnicos y de género, haciéndose interdisciplinaria ${ }^{1}$. Este retorno, que se ha tendido a denominar neovanguardia (Carrasco 1988; Galindo 2009, 2013), reitera el gesto crítico de la vanguardia y retoma los procedimientos estéticos con que ésta inauguró la época contemporánea ${ }^{2}$. En esta literatura se puede observar, tal como Carrasco (1988) lo ha identificado, una radicalización de la obra literaria en términos de expansión de los significantes mediante el uso de múltiples soportes textuales que no se limitan al libro como objeto primordial de la cultura, y que se manifiesta, por ejemplo, en la poesía experimental, visual, sonora y objetual, así como en la incorporación de variados referentes que evidencian la relación entre la obra literaria, la vida y la política, y en una modificación en las formas en que se desarrolla la comunicación literaria.

En el proceso de retorno de la vanguardia en Hispanoamérica, Galindo (2013) ha identificado dos actitudes: una de carácter hipervitalista que se define por una fuerte vinculación con los procesos vitales, sociales y políticos que sacuden al continente, y otra de carácter hiperartística que se distingue por su afán de hacer del lenguaje literario el centro de reflexión. Grupos como "El Techo de la Ballena” y "Tráfico" en Venezuela, el "Nadaísmo" colombiano, los "Tzánzicos" en Ecuador, los "infrarrealistas" en México, "Tribu No" y "CADA" en Chile, así como "Hora Zero" y "Kloaka" en Perú se vincularían a una actitud hipervitalista, mientras que en la estética neobarroca y neoconcreta en Argentina, como es el caso de Diagonal Cero y Los Huevos del Plata, habría una actitud hiperartística, no obstante, "la actitud vitalista atraviesa el proceso en su conjunto" (Galindo 2013: 13).

En estos grupos podemos observar un cuestionamiento de la autonomía del arte, pues la urgencia histórica en el continente impulsó en los jóvenes escritores la necesidad de testimoniar su propio tiempo, sumarse a los movimientos sociales y darle voz al discurso ideológico de la época, razón por la cual se estrechan los vínculos entre texto y contexto. Se trata, en este sentido, de una neovanguardia integral e integradora; integral, en tanto que en su praxis convergen elementos estéticos, políticos y vivenciales, e integradora, en tanto que renueva los vasos comunicantes entre la poesía, las artes plásticas y la performance, haciendo de la poesía una acción de arte.

Las investigaciones de Iván Carrasco $(1988,2002)$ y de Oscar Galindo $(2004,2009)$ sistematizan estas innovaciones en el contexto chileno e hispanoamericano.

2 Para Peter Burger, la gran deuda de la vanguardia es nunca haber cumplido los objetivos radicales que se propuso, en tanto que el cuestionamiento a la institución del arte se habría convertido en una actitud artística (1974: 107) que, al ser performativizada de forma repetida en la neovanguardia, termina perdiendo el efecto de shock y la autenticidad original. La lectura de Hal Foster (2001), en cambio, es que ésta pretende retomar los "procedimientos de las vanguardias de los años diez y veinte, como el collage y el ensamblaje, el ready made y la retícula" (2001:3), pero se trata de un retorno radical, de una recuperación y relaboración crítica que tensiona las categorías de evolución y desarrollo en la historia del arte. En este sentido, para Foster, ésta no es una mera réplica, pues ambas propuestas difieren en sus propósitos, de modo que "si la vanguardia histórica se centra en lo convencional, la neovanguardia se concentra en lo institucional" (2001: 19). 
En este contexto, Hora Zero ${ }^{3}$, movimiento peruano surgido en los 70, es uno de los grupos más interesantes y heterogéneos del Cono Sur. Encabezado por Juan Ramírez Ruiz y Jorge Pimentel, este grupo congregó, entre otros, a escritores con registros poéticos diversos, y aunque todavía está en discusión quiénes fueron sus integrantes, un breve recuento debe considerar a Tulio Mora, Enrique Verástegui, Jorge Najar, Mario Luna, Julio Polar, José Cerna y José Carlos Rodríguez. A treinta años de su surgimiento, y luego de múltiples balances, recopilaciones y recuentos literarios, es necesario preguntarse por el proyecto estético de una figura poco nombrada y poco estudiada en el contexto grupal: la poeta y narradora Carmen Ollé.

Nuestra hipótesis es que Noches de adrenalina (1981) de Carmen Ollé amplía y actualiza en clave de género las directrices de la poesía integral de Hora Zero. En esta obra la metarreflexión y la intertextualidad tienen como finalidad construir una genealogía crítica que posibilita que la voz poética construya un marco discursivo para reflexionar sobre la escritura. La condición hipervitalista del poema total se actualiza en dos dimensiones: por una parte, en la poética de los espacios donde se contrastan las ciudades de Lima y París y, por otra parte, en la escritura de un cuerpo en crisis. La relación entre arte y política, en cambio, implica un desplazamiento desde el compromiso social enarbolado por HZ, a una crítica desde el cuerpo mujer.

Para fundamentar esta propuesta examinaremos las características que presentó la neovanguardia en el grupo HZ, y cómo en su metatextualidad se presenta la relación arte política y vida, para, finalmente, analizar qué dimensiones adquieren estos aspectos en la obra de Ollé.

\section{La neovanguardia en el Perú: Hora Zero}

Hora Zero surge en un momento convulso de la historia, marcado, entre otras cosas, por la revolución cubana, por la confianza en el "hombre nuevo" de la revolución, por la muerte del Che Guevara, por múltiples acontecimientos del año 1968 (mayo del 68 en París, la matanza de Tlatelolco en México, la Primavera de Praga), y a nivel local, por la guerrilla en el Perú y la asunción del socialismo militar con el gobierno dictatorial de Juan Velasco Alvarado.

Se trata de un grupo de extracción media y trabajadora, varios de ellos provincianos $^{4}$, que constituyen la primera generación de sus familias en acceder a la educación superior ${ }^{5}$. En este sentido, son el síntoma del fenómeno sociocultural de la migración, fenómeno que cambió el rostro de una Lima centralista, segregacionista y marginadora que vivía de espaldas al Andes y la Amazonía. A este respecto, José

En adelante, mencionaremos a este grupo por su sigla $\mathrm{HZ}$.

4 Provenientes de Chiclayo (Ramírez Ruíz), Huancayo (Mora), Pucallpa (Nájar) y Chachapoyas (Cerna), entre otros, con excepción de Verástegui (proveniente de Cañete, provincia cercana a Lima), Pimentel y Ollé, limeños de nacimiento.

$5 \quad$ José Miguel Oviedo tempranamente destacó este aspecto indicando: "El punto de encuentro de varios de los poetas del 70 y, en más de un sentido, el foco de irradiación, fue la Universidad Federico Villareal, de Lima, particularmente, su Facultad de Educación" (1973:13), lo que se contradice con la tradición de la Universidad de San Marcos como lugar de preferencia de la actividad poética universitaria. Oviedo explica este fenómeno debido a que, como institución recientemente creada, ésta captaba un estudiantado preferentemente provinciano, que hizo de las aulas y pasillos de la sede de la populosa calle Colmena un lugar de debate político y poético, desde donde surgió HZ. Se trata, entonces, de: "hijos de los remotos obreros o maestros de oficio provincianos, [que] se habrían convertido en universitarios, accedían a los bienes culturales de la capital y aun al ejercicio literario, compitiendo (o avasallando a) otros jóvenes de clase media limeña, salidos de buenos colegios y con expectativas mucho más abiertas y promisorias" (1973:14). 
Miguel Oviedo ha apuntado que estos jóvenes aportan un rasgo casi desaparecido a esas alturas en la literatura peruana: "el espíritu regionalista, esa esperanza de articular las formas de cultura local en un solo proyecto de alcance nacional", mediante un "afán descentralista" (1973: 12), razón por la cual buscaron expandirse a provincias mediante filiales de su revista homónima.

$\mathrm{Su}$ condición neovanguardista deviene de la toma de conciencia de una posición de vanguardia ${ }^{6}$ que se plasma tanto en los documentos metarreflexivos, en las declaraciones de sus integrantes, y en las obras poéticas de algunos de ellos (especialmente de Juan Ramírez Ruiz y Jorge Pimentel), así como en la relación que establecieron con otras artes, integrando, en distintos niveles y momentos, artistas provenientes de diversas disciplinas?

Esto, junto con la comunicación que tuvieron con otros grupos ${ }^{8}$, los hizo pensarse como parte de una comunidad de sentido que está en concordancia con el espíritu de la época y las necesidades de cambio que urgían tanto en lo social como en lo poético. En la discursividad de HZ confluyen dos dimensiones por las cuales pueden ser considerados un grupo de neovanguardia, aspectos que analizaremos en este apartado: la metarreflexión como forma de posicionamiento literario, y una actitud hipervitalista que se plasma en la relación entre arte, vida y política.

\subsection{Posicionamiento metatextual de Hora Zero}

De los distintos documentos que dan cuenta de la toma de posición del grupo, consideraremos principalmente "Palabras Urgentes" (1970), "Poesía Integral" (1971), "Nosotros tenemos la razón" (1970) y "Contragolpe al viento" (1978)9 , pues constituyen el núcleo de su reflexión metatextual ${ }^{10}$ y permiten situar el proyecto común ${ }^{11}$.

6 En "Contragolpe al viento" (1978) se reconocen como: "MOVIMIENTO CULTURAL REVOLUCIONARIO MARXISTA LENINISTA y VANGUARDIA - en el campo de la cultura- DEL PROLETARIADO, CAMPESINADO Y DE TODAS LAS CAPAS OPRIMIDAS DEL PUEBLO PERUANO" (Cit. en Mora 2009: 550).

7 Al respecto, Tulio Mora propone: "Por eso son miembros de HZ pintores como Carlos A. Ostolaza y Oswaldo Higuchi, ya poseedores de un sólido prestigio, los actores Pietro Luna (...) y Edison Mego, el artista gráfico Alberto Escalante, diseñador de casi todas las publicaciones horazerianas, el mismo Jorge Fernández, el fotógrafo Jorge Verástegui, el caricaturista Julio Polar y los entrañables trotamundos Alberto Colán y Mateo Morales" (2009: 33).

8 Especialmente con los infrarrealistas mexicanos liderados por Roberto Bolaño, Mario Santiago Papasquiaro y Bruno Montané. A nivel metatextual, esta comunicación se concretiza, por ejemplo, en la carta "Rasgar el tambor, la placenta" (1977) que los infrarrealistas le escribieran a Hora Zero adhiriendo a sus propuestas y, un año después, en la signatura del documento común "Contragolpe al viento".

9 Los cuatro metatextos citados se encuentran consignados en Mora (2009).

10 Entendemos por metatextualidad, siguiendo a Mignolo (1986), un proceso secundario de conceptualización, que dice relación con los bordes disciplinarios y estéticos que trazan los integrantes del campo literario, presentando su propia noción de texto, un modelo textual y su sistema de preferencias, entre otros aspectos. El metatexto, en tanto documento programático, se actualiza en diversos tipos de discurso en los cuales la metarreflexión se presenta de manera explícita (como en las artes poéticas, en los manifiestos, declaraciones), y otros en que se presenta de forma implícita (como entrevistas, ensayos, prólogos, epílogos, o textos poéticos que en parte de su estructura presentan una reflexión de carácter metatextual).

11 Una revisión compleja y completa de la discursividad de este grupo no debe soslayar la signatura de los manifiestos, ya que esto revela que la adhesión y consecuencia escritural es principalmente de poetas como Pimentel y Ramírez Ruiz, quienes firman, particularmente, los primeros tres documentos considerados en esta revisión, mientras que "Contragolpe al viento" es quizá la proclama con mayor número de adherentes. Textualmente, esta diferenciación se plasma en que la praxis escritural de otros integrantes del grupo que, como Mejía, Cerna, Nájar y, fundamentalmente, 
En términos generales, esta discursividad les permite una violenta irrupción en el campo literario mediante el cuestionamiento de la institucionalidad artística vigente, y atacar el estatus del arte en la sociedad burguesa. "Palabras urgentes" es un texto que hibrida la reflexión sobre el papel del arte en la transformación política con una acérrima crítica a la institución literaria, rasgo que surge de la toma de consciencia de sentirse "escritores con una nueva responsabilidad, con una nueva actitud ante el acto creador, ante los hechos derivados de una realidad con la que no estamos de acuerdo" (Mora 2009: 535). A partir de allí, el foco de sus ataques se centra en la crítica literaria y en la poesía contemporánea peruana, la que descalifican como poco original: "después de Vallejo sólo ha sido un hábil remedo, trasplante de otras literaturas” (2009: 535).

La discursividad de HZ, en este manifiesto en particular, podría calificarse de "parricida", pues sus autores establecieron una distancia crítica con la generación del 60 , sujetos de quienes sólo se diferencian por unos pocos años ${ }^{12}$. Esta actitud desafiante se complementa con inéditos, y a esas alturas nostálgicos "duelos poéticos" y actas de acusación a escritores que consideraban "poco consecuentes" como Nicanor Parra y Pablo Neruda. Junto con lo anterior, se propusieron hacer de sus lecturas poéticas y recitales un medio para la concientización, como "prolongación del acto creador del poeta" (Cit. en Oviedo 1973: 140). Sus acciones se basaban en la convicción de que la poesía tiene un poder revolucionario y transformacional, y constituye un medio para el cambio social, por lo que el escritor debe tener un papel activo en la sociedad ${ }^{13}$.

En su metarreflexión plasmaban la problemática relación entre arte, política y vida, que son dimensiones fundamentales para comprender cómo este movimiento estrecha los límites entre su proyecto estético y la función ideológica de su discurso.

\subsection{La dimensión hipervitalista del poema integral}

El poema integral, propuesto fundamentalmente por Ramírez Ruiz en el manifiesto "Poesía integral" (1971), responde a las características de una poesía totalizante o absoluta que tiene por finalidad constituir un universo simbólico de expresión, donde todas las posibles conexiones con la vida, con la realidad acontecida -histórica- y aconteciente -actual- son deseables.

Verástegui, se alejan de lo coloquial y popular. De este modo, proyectos singulares como los de Verástegui y Ollé proponen interesantes aperturas de la voluntad integradora del grupo.

12 En este contexto epocal se torna necesario revisar la periodización de las generaciones, tal como ha propuesto García-Bedoya (2012), para quien los poetas del 60 y del 70 podrían constituir una sola promoción, lo que se reafirma si pensamos que, más que una ruptura total, la crítica ha destacado una continuidad en el horizonte de preferencias textuales (Cfr. Oviedo 1973; Guillén 2006; Galindo 2009), puesto que los poetas de HZ amplían las indagaciones estéticas que ya habían iniciado escritores generalmente signados como pertenecientes a la generación del 60, tales como Antonio Cisneros, Luis Hernández, Rodolfo Hinostroza, Abelardo Sánchez León y Mirko Lauer, entre otros. De este modo, algunos de los aspectos a los que se da continuidad son: "la narratividad, la fragmentación y la simultaneidad del discurso, las posibilidades del humor y la desfachatez, diálogos con la historia y los aportes de las ciencias sociales o la exploración de lo cotidiano" (Chueca 2006: 37).

13 Aunque como movimiento le imprimen dinamismo al sistema poético, sobre esta discursividad se han planteado críticas importantes que tienen que ver con la consecuencia. José Miguel Oviedo (1973) resalta, por ejemplo, criticar la falta de espacio en los medios nacionales, pero publicar poemas en el diario El Comercio y entrevistas en otros medios importantes, poner en cuestión los círculos poéticos que leen en la Biblioteca Nacional y, sin embargo, organizar allí mismo una serie de lecturas, entre otros aspectos. Así mismo, desde la distancia crítica, Luis Fernando Chueca (2006) se pregunta por la condición estratégica de los manifiestos, declaraciones y polémicas horazerianas, los que podrían haber sido motivados tanto por la convicción ideológica, como por la conciencia de que tal discursividad, aunque arriesgada, les permitiría situarse en el espacio artístico, tal como finalmente sucedió. 
En su formulación recurrieron al marco ideológico que los cobija, de modo tal que su finalidad fue que "los contenidos revolucionarios se expresen en formas revolucionarias" (Cit. en Mora 2009: 539), por lo cual el lenguaje literario se transforma en un terreno de democratización. En este sentido, la poesía integral se caracteriza por una apertura lingüística hacia el "habla popular", en el "argot, en los giros populares y en la invención de nuevos términos" (Cit. en Mora 2009: 540), por eso el lenguaje trata de registrar desde lo sensible a lo escatológico. A este respecto, la crítica ha enfatizado en la vocación exteriorista de esta propuesta, debido a la influencia que ejerció sobre este grupo el proyecto literario y de vida de Ernesto Cardenal, especialmente con su libro Hora 0 (de 1957), texto que tempranamente da cuenta de la relación del texto poético - de características narrativas y conversacionales- con los problemas de la contingencia social.

La estética horazeriana es integral y vitalista, tanto por su acercamiento a la "realidad", como por la voluntad, un tanto quimérica, de extender el acto creador hacia la vida, puesto que según sus palabras: "es necesario hacer de la vida una obra de arte y de la obra de arte un ente vivo generador de alegrías y fuerza constructiva" (2009: 542), entendiendo que ésta se encuentra en concordancia con la búsqueda del hombre nuevo.

Estos postulados, según Luis Fernando Chueca (2006), se manifestaron principalmente en dos dinámicas representacionales que los poetas horazerianos generaron a nivel textual. La primera de ellas tiene estricta relación con la presencia de personajes en el poema, figuras cercanas a la experiencia del autor textual, es decir, de jóvenes migrantes provincianos en Lima o pequeños burgueses en decadencia económica. En la segunda dinámica, el hablante, también cercano a la voz autorial, "expresa su mirada y su comprensión de la ciudad y del país (y de la poesía en la sociedad)" (Chueca 2006: 35). La obra poética de Carmen Ollé, con sus particulares características, se acercaría a estas dinámicas.

En su "Prólogo" a la Antología de la poesía peruana. Fuego abierto (2008), la misma Ollé indica como uno de los logros de este grupo el haber hecho de la poesía un lugar de incorporación del universo provinciano, de poblar el espacio poético con la vida de "personajes comunes y corrientes" (2008: 12), y de representación de la vida de los jóvenes migrantes que irrumpen en las históricas calles de Lima. Por esta razón, con su "nueva" estética, "liquidaron los resabios de sensibilidad aristocrática o pequeñoburguesa con su afán integracionista, la utopía del poema total y el ideal de formar una comunidad de poetas" (2008: 12); sueño que, por cierto, se fue diluyendo por la imposición de tiempos violentos, producto de los regímenes militares y de la guerrilla interna impulsada por Sendero Luminoso.

\subsection{El discurso político en Hora Zero}

A partir de su autodenominación como vanguardia cultural del proletariado y su discursividad crítica, buscan dar cuenta de la escritura como terreno de conflicto, en donde también operan los contrastes de clase (Mora 2009). Su metatextualidad se encuentra impregnada de un compromiso político e ideológico con la revolución social en Hispanoamérica, y hacen suya la consigna que en los años 20 planteó José Carlos Mariátegui, en tanto que el arte requiere del absoluto de la época y, siendo ésta una época convulsa, la poesía debe impregnarse de las circunstancias y la discursividad política. 
El manifiesto "Palabras urgentes" les permitió una crítica situada, ya que parten del sentimiento de estar en una sociedad estancada en valores tradiciones tanto en lo moral como en lo literario: "Hemos nacido en el Perú, país latinoamericano, subdesarrollado, hemos encontrado ágiles ruinas, valores enclenques, una incertidumbre fabulosa y la mierda extendiéndose vertiginosamente" (Cit. en Mora 2009: 535). Debido a su origen, formación ideológica (directamente marxista leninista como reconocieron en "Contragolpe al viento"), y a las circunstancias históricas de su tiempo, se sintieron parte del devenir social y buscaron participar de la revolución llevando al espacio literario los conflictos del Perú: "Queremos cambios profundos, conscientes de que todo lo que viene es irreversible porque el curso de la historia es incontenible y América Latina y los países del Tercer Mundo se encaminan hacia su total liberación" (Cit. en Mora 2009: 535).

En su momento, esta articulación fue leída críticamente por Oviedo, calificándolos como un grupo agitprop (1973: 13), cuyo discurso, más panfletario que estético, estaba lleno de lugares comunes (1973: 16). Oviedo, en este sentido, cuestiona ciertas afirmaciones, tales como: "Si somos iracundos es porque esto tiene dimensión de tragedia. A nosotros se nos ha entregado una catástrofe para poetizarla. Se nos ha dado esta coyuntura para culminar una etapa lamentable y para inaugurar otra más justa, más luminosa" (Cit. en Mora 2009: 538), ya que de su retórica se desprende un sentido apocalíptico, auroral y mesiánico, en la que no habrían considerado las verdaderas posibilidades de repercusión de su discurso.

En consecuencia, y siguiendo a Mora (2009), diremos que las características del poema integral se resumen en los siguientes aspectos: 1) una tensa relación entre la tradición literaria y el surgimiento de un discurso popular y marginal de nuevos sectores de la sociedad; 2) la predominancia de una "poética de la experiencia", de tipo vitalista; 3) la experimentación con la lengua y la introducción, en el discurso literario, del habla popular; 4) la influencia y la experimentación con otros géneros y discursos, entre los que se incluyen la prosa poética, la dramaturgia, el ensayo, lo audiovisual, lo periodístico, entre otros; $y, 5$ ) la apertura del espacio poético a nuevos perfiles humanos.

\section{NOCHES DE ADRENALINA: AMPLIACIÓN Y ACTUALIZACIÓN DE LA POESÍA INTEGRAL}

Los estudios literarios han desplazado la obra de Carmen Ollé desde el ámbito discursivo de la estética horazeriana, gestado en los 70, hacia la "generación" de los 80, debido al año de publicación de Noches de adrenalina. Ello ha implicado que se la lea, con bastante razón, como un texto fundacional desde el punto de vista de género, anticipatorio del discurso que tendrán las poetas de mediados de los 80 en el Perú.

Para críticos como Susana Reisz, por ejemplo, fue Ollé quien consagró una "abierta provocación en un lenguaje sexualizado y des-romantizado, duro y sarcástico, “impropio" de una boca femenina” (1996: 124), aspecto ya anticipado por la fallecida María Emilia Cornejo y que, según Roland Forgues (2004), continuarán poetas como Dalmacia Ruiz-Rosas, Patricia Alba, Mariela Dreyfus, Rocío Silva Santisteban y Violeta Barrientos ${ }^{14}$. En este sentido, nos parece que una deuda pendiente de la crítica

Otras lecturas como las de Reisz (1998), Forgues (1999), Vittoria Borsó (1998) y Paul Guillén (2006) profundizan en estas relaciones. 
literaria es poner en diálogo la poesía escrita por mujeres con los pares masculinos, para tener una mirada más amplia de los procesos escriturales y de los textos en relación con la época en que surgen.

En este caso particular, queremos analizar las convergencias y divergencias entre la obra de Ollé y la estética de HZ, algo que ha sido apuntado por algunos críticos, mas no analizado en profundidad. En este sentido, José Güich Rodríguez (2006) indica lo siguiente: "En 1981 los corrillos literarios de Lima fueron sacudidos, desde sus cimientos, por un poemario titulado Noches de adrenalina. Su autora, la limeña Carmen Ollé, había nacido en 1947. Pertenecía, por lo tanto, a una promoción anterior de escritores, si nos atenemos a los criterios cronológicos" (2006: 165), razón por la cual este mismo estudioso la considera como una "quinta columna" dentro del movimiento HZ (2006: 167).

Para Eduardo Espina, por otra parte, constituiría una de las voces más importantes del setenta: "como integrante del Movimiento Hora Cero [sic], comenzó a publicar en los setenta, aunque su primer libro, Noches de adrenalina, recién conoció la imprenta en 1981. Quizás desde Blanca Varela que una mujer no lograba tanto reconocimiento en la poesía del Perú" (1993: 692). Más discreto en sus comentarios, Tulio Mora (2009) menciona su obra como uno de los textos que, diez años después de publicado "Poesía integral", retoma esa estética como espacio aglutinador de múltiples discursos.

Esta lectura enfatizará, entonces, en la relación de la obra con la estética del poema integral. Por esta razón planteamos un análisis a partir de las categorías que surgieron del estudio de la metatextualidad horazeriana, para analizar las nuevas dimensiones que esta estética adquiere en su obra.

\subsection{Metarreflexión e intertextualidad: La noción de escritura en Noches de adrenalina}

La obra de Carmen Ollé se construye en base a una compleja red de citas y de comentarios que permiten una reflexión sumamente culta sobre la escritura y, a la vez, un diálogo intertextual a través de lo cual se funda una genealogía poética particular. La intertextualidad constituye, entonces, una voz doble que le permite cuestionar o validar el estatus del conocimiento y el espacio escritural.

En uno de los primeros textos del poemario ${ }^{15}$, la voz poética inicia su discurso con un posicionamiento que se acerca a la poesía confesional estadounidense: “¿Escribir es una veleidad que dice o disiente / para una mujer casada? / ¿Silvia Plath y su Hollywood sin ventanas / o las cartas de Diane de Prima?" (199716: 22).

Estos primeros versos nos permiten ver dos elementos importantes. En primer lugar, el cuestionamiento de los espacios escriturales de la mujer, específicamente, el problema del hogar como lugar asignado a la mujer, espacio simbólico que muchas escritoras resignifican, generando desde allí una epistemología íntima, una forma de conocimiento diferente de la razón logocéntrica que se acerca a lo intuitivo, a lo sensual y a los sentidos que brotan de espacios particulares como la casa. No obstante, la actitud de la hablante es muy distinta. La retórica de la pregunta parece interpelarnos desde el hastío y desde la crisis productiva de ese espacio. Así, el

5 Aclaramos que aunque en el libro no se indican los títulos de los poemas, hemos optado por denominarlos de acuerdo al primer verso.

16 Todas las citas del texto corresponden a la versión bilingüe de la obra editada por Floricanto Press en 1997. 
Hollywood sin ventanas de Plath alude a su poesía confesional -una estética donde la voz de la hablante, al igual que en el poema integral, no se aleja de las vivencias y sentimientos de la autora textual-, y a una estética que presenta el espacio íntimo como lugar de conflicto. La alusión a Diane di Prima, por otra parte, tiene que ver con el posicionamiento de una mujer escritora, feminista, ligada a los beatnik, que en sus Cartas revolucionarias (1971), propone una poética de la revolución y la destrucción. A propósito de tales alusiones, entonces, se hace patente que esta genealogía se basa en la tradición de escritoras estadounidenses revolucionarias de la palabra poética, que presentan una mirada crítica de la sociedad y de los espacios de represión.

En esta reconstrucción se van incorporando progresivamente otras referencias:

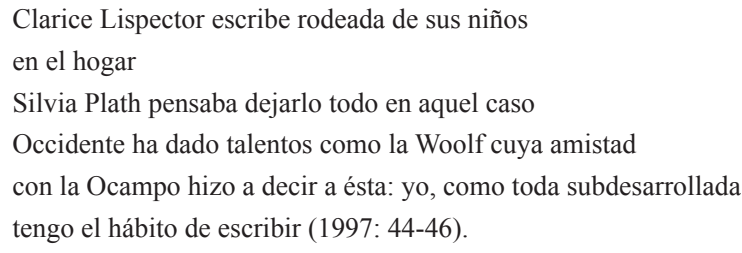

En estos versos las alusiones siempre apuntan a la búsqueda de un espacio propio de escritura, de un "cuarto propio", al decir de Virginia Woolf, territorio simbólico desde donde debe surgir una expresión propia. Ese espacio conflictivo, que genera en la voz poética sentimientos contradictorios, se presenta de la siguiente manera: "Estando la mayor parte del tiempo en casa / poesía y prosa se desposan como en el acto de amor" (1997: 78), y ello da pie a una reflexión escritural mediada por la experiencia del cuerpo.

En Noches de adrenalina, además, aparece otra serie de discursos intertextuales alusivos a la filosofía moderna, lo que posibilita la construcción de un marco metadiscursivo con el cual el texto dialoga de forma crítica a través de una doble voz. Los primeros versos del libro dan cuenta de ello: "Tener 30 años no cambia nada salvo aproximarse al ataque / cardiaco o al vaciado uterino. Dolencias al margen / nuestros intestinos fluyen y cambian del ser a la nada" (1997: 14). La alusión se da aquí en relación con la filosofía existencialista sartreana, específicamente a la obra El ser y la nada (1943). El texto poético, en este sentido, se abre con la idea de un sujeto vacío, de un sujeto en potencialidad múltiple: crear su mundo, transformarse en ser y rebelarse contra la nada. Así, la escritura parece ser el intento por la construcción del ser, por eliminar ese vacío (nihil) para formar una consciencia que supera la nada, pero será el cuerpo-mujer el que evidenciará ese horror al vacío (horror vacui) que la escritura trata de superar.

La metarreflexión, de este modo, aparece relacionada con los puntos de fuga desde donde la escritura debiera fluir:

el pensamiento y el flujo:

estoy agotada aquí en la espera del ritual

la retención de ideas corresponde a los flujos

reprimidos

he olvidado a mi madre en la cápsula que me parece

hoy la pubertad y el lecho donde recostándose a mí 
mostraba preocupada el algodón limpio (...)

perdí miedo a mis ovarios

a la ceguera que amenazaba al contrariarlos (1997: 86).

Cuerpo, pensamiento y texto se funden en una imagen escritural que, de acuerdo a Francine Masiello, representaría una "correspondencia entre la materialidad de la carne y lo concreto del lenguaje" (2001: 382). La escritura se metaforiza en los flujos corporales, razón por la cual la escritura constituye un cuerpo textual en crisis: "la impotencia de ligar con el texto proviene / de la práctica erótica mutilada (desempleo sexual)" (Ollé 1997: 24). Más adelante, esa reflexión vuelve a lo escatológico: "Bella palabra hacer $=$ poiesis / se hace un verso el amor y la caca por algo de juego / natural" (1997: 32).

La noción de escritura que aparece en el poemario, entonces, parece presentarse en un movimiento pendular que oscila entre construir un espacio del decir, y que este decir cuestione el valor de la palabra en sociedad. Por este motivo, la voz poética se refugia en lo obyecto porque es lo que la constituye como ser: "lo obsceno sigue siendo para mí una prolongación / de la incertidumbre” (1997: 94), dice la voz lírica para reforzar la idea de que en la escritura, en tanto integralidad, confluyen todos los ámbitos de la vida.

La metarreflexión en Noches de adrenalina, en consecuencia, apunta a la construcción de una genealogía discursiva: las alusiones a poetas como Sylvia Plath, Diane di Prima o Clarice Lispector se relacionan, en un primer nivel, con la estética del poema confesional, pero en un plano más profundo, con la necesidad de establecer una irrestricta sintonía entre la historia de vida y la escritura que, en este caso, se presenta mediante comentarios acerca de cómo la vida diaria también afectaba su proceso escritural. Así, parece ser que la voz poética, y por supuesto, la autora, quisiera decirnos que su propio proceso y condición es, precisamente, el de la dificultad.

\subsection{La actitud hipervitalista en Noches de adrenalina}

Si para la estética de HZ el afán totalizante de la poesía integral está dado tanto por la apertura lingüística hacia las voces y expresiones populares, como por la textualización de la actividad vital del autor en la obra literaria, en Noches de adrenalina esos aspectos se encuentran presentes mediante una estrecha relación con la experiencia de vida de la autora, por lo que la voz poética adquirirá la condición de un flâneur que se desplaza entre Lima y París. La apertura hacia los variados aspectos de la vida que propone el poema integral aquí se concretizará en la escritura de un cuerpo en crisis.

Esta apertura se inicia, como en la categoría anterior, con una cita textual. En este caso, corresponde a la obra de Gastón Bachelard: “¿Dónde está el peso mayor del estar allí / en estar o en el allí? / En el allí que sería preferible llamar / un aquí- ¿debo buscar primeramente mi ser?" (1997: 18). Esta cita de Poética del espacio (1957) nos permite pensar en la construcción de una poética de los espacios oposicionales.

Los espacios oposicionales a los que se alude poéticamente son las ciudades de Lima y París, territorios a través de los cuales la voz transita a través de la memoria. De alguna manera, y siguiendo la poética de Bachelard, estas urbes representan dos tipos de espacios: por una parte, París y el espacio del mundo, por otra, Lima y 
el espacio de la intimidad; razón por la cual nostalgiar desde París lleva siempre a las alejadas calles de Lima. En este sentido, las alusiones a Perú como un país en conflicto darán paso a reflexiones sobre un cuerpo en crisis, estableciendo así un continuum entre el cuerpo-mujer y el cuerpo social.

En uno de los primeros poemas ("De mis contemporáneas me alejan las dificultades de no ser trivial"), París es el principal referente, el escenario desde donde transcurre la acción:

En la Gare du Nord cerré los ojos muy fuerte.

Vi París después de un viaje largamente sentada en la butaca del ferrocarril con la pequeña en brazos

y la torre Eiffel partida por la niebla

¿Qué son los Campos Elíseos o la Gioconda sino el ménage

delegado a las jóvenes muchachas del tercer mundo?

Lavar pisos

refregar las estrellas (1997: 20).

Mientras la hablante parece arribar por primera vez a la ciudad luz, ésta es presentada desde una niebla que la corona como ciudad fantasma (Güich 2006). Así, la voz, en correlación con la vida, se sitúa desde la experiencia de una migrante en un territorio que se esperaba amable, pero que resulta hostil, tal como lo presenta en otro poema:

De los jardines de la U imaginaba París como un barrio cálido donde alcanzar el espíritu de los impresionistas hoy pasé en París un invierno escarchado una navidad que podría haber sido postal si no fuera porque estas celebraciones pierden todo sentido lejos del clima familiar y las postales no se pueden vivir (su naturaleza es retiniana) (1997: 40).

La naturaleza retiniana de París constituye la imagen invertida del deseo de juventud. La ciudad se ha convertido en un territorio árido, de incomunicación y vacío, idea que se contrapone con la imagen universal de sus museos y sus calles turísticas, cual románticas postales derruidas por la realidad de la migrancia de las "jóvenes muchachas del tercer mundo", cuya experiencia de la ciudad no está en el devenir de los bulevares callejeros sino en el ménage, en los trabajos en las casas donde deben "lavar pisos / refregar estrellas". Lo que parece presentarnos este fragmento es el París de una paria, la experiencia de una ciudad donde se vive con extrañamiento y lejanía, por lo cual es natural que desde allí se nostalgie Lima y la familia que se ha dejado atrás: es allí y no en París en donde lo familiar adquiere sentido, aspecto que aparece más adelante en el mismo poema:

P es una ciudad en la que pasé al azar una fiesta finita en los límites de una soledad llamada cortesía, en el bulevar Saint Michel tomé un capuchino en perfecta nostalgia de mi ambiente esforzándome por encontrar la Colmena noctámbula 
Notre Dame fue vista mientras bebía un coñac tibio en la noche cené puerco dulce en restaurantes vietnamitas y era como volver a la calle Capón en Lima, la necesidad absurda de rencontrarnos siempre millas de distancia con una vaga identidad (1997: 40).

De este modo, la poética de los espacios -el aquí que es París, el allí que es la lejana Lima- se sintetizan en la escritura y se contraponen con melancolía, amalgamando el imaginario de la ciudad luz con las calles del centro histórico (la Avenida Nicolás de Pierola, más conocida como Colmena) y del barrio chino (la calle Capón). Sin embargo, y tal como Güich Rodríguez (2006) sostiene, la presentación es tragicómica pues la imagen de postal parisina comparte lugar con las alicaídas calles limeñas. Se activa, así, una memoria en contrapunto que fluye entre deícticos de tiempo y espacio nostalgiando desde el presente, pero de manera conflictiva, motivo por el cual la identidad está en un estado liminar, y se presenta como un recuerdo que se reafirma en el afuera, en el espacio del mundo.

Lima, por otra parte, es el espacio íntimo, es el lugar de la escritura del cuerpomujer en tránsito, del cuerpo en cambio, tal como lo presenta en el primer poema:

He vuelto a despertar en Lima a ser una mujer que va midiendo su talle en las vitrinas como muchas preocupada por el vaivén de su culo transparente.

Lima es una ciudad como yo una utopía de mujer (1997: 14).

La voz poética, entonces, está incardinada (en términos de Rossi Braidotti (2004)), es decir, se encuentra encarnada, toma forma en un cuerpo que se nos aparece como un cuerpo en crisis: un cuerpo que pierde dientes como pierde su forma o asume una nueva entre el postparto y los cambios hormonales ("Hoy perdí un diente / (...) ¿La belleza de las piezas naturales intactas no es un / humanismo narcisista?" (1997: 24). O como, por ejemplo, más adelante, en el mismo poema, dice: "Tengo 30 años (la edad del stress) / Mi vagina se llena de hongos como consecuencia del / primer parto"). (1994: 14).

Más adelante, en el poema "Hay que huir de los techos...", recursivamente se retorna al mismo tema, pero ahora la escena se sitúa en la consulta del dentista: "la enfermera me da los precios de los dientes / -los dientes han subido- me avisa con firmeza" (1997: 34). Los conflictos existenciales que detonan de la escritura de ese cuerpo en crisis derivan tanto en reflexiones sobre el acceso económico al objeto, como a las significaciones sociales sobre la belleza y el cuerpo-mujer: "Ahora me costaría un ojo de la cara recomponer mi belleza / Trataré de no reír lo más que pueda, ¿pero mi destino / depende de una porcelana, de un pobre metal, quizá de / la resina o del acrílico?" (1997: 34).

La voz poética, como un fluir de consciencia, va comentando aspectos de la vida relativos a un cuerpo cuyos cambios generan extrañeza y, así, va generando un tejido donde se incorporan alusiones múltiples y referencias heteróclitas, como a aspectos "sacros y profanos" de la cultura. Por este motivo, el lenguaje se devuelve hacia lo escatológico, hacia el espacio más recóndito de lo humano: "defecamos con soltura y es el único motor intacto / se corona una era escatológica // LA CACA ES TAN PODEROSA COMO UN PEQUEÑO COMPLEJO” (1997: 26). 
En tanto poesía integral, el texto literario se mueve por espacios liminares donde el decir está en juego: en la apuesta entre lo que se puede enunciar y lo que no, entre lo que está fuera o dentro en la dialéctica del espacio del mundo y del espacio íntimo, se elige la subversión, es decir, se escoge hablar desde una posición marginal aquello que el discurso tradicional no enuncia, para así construir una "mística de relatar cosas sucias" (1997: 30), tal como dice la hablante.

\subsection{Poema integral en Noches de adrenalina: Del discurso político a la crítica de género}

Si para HZ la relación entre arte y política estaba dada por la crítica social y un cuestionamiento de los valores tradicionales de la sociedad peruana, la obra de Ollé pone en entredicho los condicionamientos sociales, y enfatiza en los elementos estructurales que afectan a la mujer de una manera política. Por esta razón, en este ámbito podemos observar un desplazamiento discursivo: se va desde el compromiso social con las clases populares, hacia una crítica de género que se compromete con el cuerpo-mujer en crisis, para desafiar las convenciones corporales, lingüísticas y escriturales.

Esta crítica, pues, se inicia situando al cuerpo en el tejido social, pero para criticar su estructura de sujeción: "Las relaciones con las partes de mi cuerpo no son teológicas / son frustraciones derivados del dolor de un cuerpo fetiche" (1997: 24). Nos encontramos aquí con una voz poética consciente del peso de las construcciones sociales que se han generado sobre el cuerpo-mujer, motivo por el cual éstas se exponen en un discurso que busca deconstruirlas, pues "en Lima la belleza es un corsé de acero" (1997: 38).

La voz poética, en este sentido, no es la única que desafía estas convenciones: también lo hacen Elsa, Sira y Margarita, jóvenes militantes marxistas que transitan por el texto como por los pasillos universitarios que frecuenta la hablante. Se convierten, así, en personajes que deambulan por las páginas, cuya presencia permite establecer un nexo entre el cuerpo-mujer y la política. Esas jóvenes aparecen ya en el primer poema:

Margarita Elsa Sira se perdían en la avenida Venezuela y colocaban carteles en la noche sobre paredes musgosas.

De día interrumpían las clases de metafísica con rabia y aplaudíamos esos cabellos sudorosos y negros sobre la espalda $(\ldots)$

Despierto y me levanto de un catre viejo estoy inclinada en el WC el culo suspendido he venido del brazo de mi compañero de clase por un solo motivo buscando a Sira a Elsa a Margarita

La militancia no es una casa vieja del Rímac pobre o hedionda y aquí sin espejos o tasas de mayólica aguantas las ganas de orinar o revientas.

La impotencia es silenciosa y corta el flujo-- (1997: 16). 
Esas muchachas militantes que circulan por las atestadas calles limeñas con carteles de cambio social y con un discurso esperanzado, son el retrato desolado de la pérdida de esas esperanzas, razón por la cual el discurso ideológico -uno de los ejes más importantes de HZ- es presentado con cierta distancia crítica. Volvemos a ver aquí la poética de los espacios: el espacio íntimo, representado por la precariedad de la vieja casa del distrito Rímac, y el espacio público o el espacio del mundo, representado por las aulas y las calles en que interrumpen con su discurso comprometido.

En estos versos se evidencia una continuidad discursiva en otros dos aspectos. En primer lugar, la irrupción en las clases de metafísica representa una ruptura en el flujo del conocimiento, es decir, un quiebre de la metafísica por la física de los cambios sociales y; en segundo lugar, una interrupción del flujo político por el flujo del cuerpo, apareciendo, nuevamente, la intersección entre el cuerpo social y el cuerpo-mujer en una sola conjunción, devenir que, en otra parte del texto, se presenta de la siguiente forma:

\author{
¿Por qué el psicoanálisis olvida el problema de ser o no ser \\ gorda / pequeña / imberbe / velluda / trasparente \\ raquítica / potona / ojerosa... \\ Del botín de la cultura me pregunto por el destino \\ ¿Por qué Genet y no Sarrazine? \\ o Cohn Bendit / Dutschke / Ulrike \\ y no las pequeñas militantes que iluminaban mis aburridas \\ clases en la $U$ \\ ELSA SIRA MARGARITA
}

Marx aromaba sus carteras como retamas frescas

qué bellas están ahora calladas y marchitas (1997: 14).

De manera similar a los planteamientos horazerianos, aquí la voz poética lleva esa crítica hacia el ámbito íntimo, corporal de la mujer, ampliando así el registro de la poesía integral. Por ese motivo, confronta las figuras de destacados militantes anarquistas europeos, participantes del ejército rojo y de Mayo del 68 en Francia y Alemania, con las pequeñas muchachas de San Marcos, cuya militancia de base se reivindica frente a figuras que han pasado a la "historia": se trata de la microhistoria de unas jóvenes que, como las flores, están "calladas y marchitas", pues son naturaleza muerta.

De este poema, entonces, surgen dos aspectos interesantes: la confrontación entre la historia oficial y la microhistoria, es decir, la impugnación de los registros oficiales donde nunca encontraremos los nombres de esas pequeñas militantes $\mathrm{y}$, en la misma línea, esta impresión desencantada remite a la pérdida de los ideales por el peso de la realidad, y a la caída de los grandes relatos de la modernidad. Por esta razón, hay que insistir en las formas en que se encuentran y desencuentran el cuerpo social y el cuerpo-mujer, dada la significación que en este texto adquiere la mención del psicoanálisis: no es una teoría nerviosa de la mujer o de la historia, sino una irónica bajada de la teoría a la "realidad".

El tránsito de esos personajes continúa en otro poema, pero su presencia refuerza la desilusión: "Elsa Sira Margarita las amo porque nadie sabe qué camino / han 
tomado sus frustraciones / estoy callada pero no ausente" (1997: 44). La relación aquí es evidente: las muchachas calladas y marchitas se contraponen con el discurso de esta mujer que está "callada pero no ausente", aludiendo paródica y críticamente a los conocidos versos del "Poema 15" de Pablo Neruda.

Parece ser, entonces, que este texto se estructura en base a la metarreflexión y la metatextualidad, pues resulta ser un pilar en cada de uno de los aspectos que hemos analizado. Éstos, a su vez, resignifican las funciones que tiene la metaxtualidad, el hipervitalismo y la política, ampliando y actualizando el registro de la poesía integral y de la estética horazeriana.

\section{ConClusiones}

El objetivo de este estudio ha sido analizar la continuidad y la ruptura entre la poesía integral de Hora Zero y la obra de Carmen Ollé. Para esto hemos revisado la noción de neovanguardia en Hispanoamérica, y analizado qué implica el retorno de la vanguardia de acuerdo a las coordenadas estéticas de este grupo, cuya propuesta se puede caracterizar como hipervitalista, dinámica y movilizadora de la vida y la política.

En Noches de adrenalina hemos podido observar que la metarreflexión, el hipervitalismo y la condición política de la poesía integral se encuentran en la obra, pero estos elementos adquieren una nueva impronta debido a que la clave de género le entrega otras directrices a la obra, que le permiten ampliar y actualizar la discursividad iniciada por Hora Zero.

De este modo, si para el grupo peruano la metatextualidad implica un posicionamiento "parricida", en el texto de Ollé esta dimensión propende a una nueva genealogía a partir de las relaciones intertextuales que configuran el horizonte estético que atraviesa el poemario. El hipervitalismo del poema integral, que en Hora Zero se vincula con la experiencia de mundo y la realidad vital del autor, en Noches de adrenalina se plasma en una poética de los espacios donde se confronta la experiencia de habitar y transitar por dos mundos distintos (París, Lima), así como en la escritura de un cuerpo en crisis que critica las convenciones sociales mediante un lenguaje desenfadado. La dimensión política, finalmente, se amplía hacia una reflexión en torno al género, pues las alusiones a las jóvenes militantes demuestran el desgarro y el vacío de las ilusiones sociales.

Habría que decir, entonces, que Noches de Adrenalina propone una escritura fragmentada y una punzante ironía que aborda temas múltiples, tales como los cambios del cuerpo, el peso de lo doméstico frente a la escritura y los deseos reprimidos, ampliando, de este modo, el registro del poema integral y la estética horazeriana.

\section{OBRAS CITADAS}

Bachelard, Gastón. 1957. La poética del espacio. Buenos Aires: Fondo de Cultura Económica. Borsó, Vittoria. 1998. "La poesía del eco en la escritura de los años 80: Blanca Varela, Giovanna Pollarolo y Carmen Ollé”. En Kohut, Karl, José Morales Saravia y Sonia V. Rose (Eds.), Literatura peruana hoy. Crisis y creación. Frankfurt: Iberoamericana. 196-217.

Braidotti, Rossi. 2004. Feminismo, diferencia sexual y subjetividad nómade. Barcelona: Gedisa. 
Burger, Peter. 1974. La teoría de la vanguardia. Barcelona: Ediciones Península.

Carrasco, Iván. 1988. "Antipoesía y neovanguardia”. Estudios Filológicos 23: 35-53. 2002. "Interdisciplinariedad, interculturalidad y canon en la poesía chilena e hispanoamericana actual”. Estudios Filológicos 37: 199-210.

Chueca, Luis Fernando. 2006. "Alcances y límites del proyecto vanguardista de Hora Zero". Intermezzo Tropical 6: 29-45.

Espina, Eduardo. 1993. "Poesía peruana: 1970, 1980, 1990". Revista Iberoamericana 164165: 687-702.

Forgues, Roland. 1999. "Cuerpo, erotismo y discurso sobre la feminidad en la poesía del Perú escrita por mujeres (1970-1995)". En Forgues, Roland (Ed.), Mujer, creación y problemas de identidad en América Latina. Mérida: Universidad de Los Andes. 133-142. 2004. Plumas de afrodita. Una mirada a la poeta peruana del Siglo XX. Lima: Editorial San Marcos.

Foster, Hal. 2001. El retorno de lo real. La vanguardia a finales de siglo. Madrid: Akal.

Galindo, Oscar. 2004. "Interdisciplinariedades en las poesías chilena e hispanoamericana actuales". Estudios Filológicos 39: 155-165.

2009. "Neovanguardias en la poesía del cono sur: Los 70' y sus alrededores". Estudios Filológicos 44: 67-80.

. 2013. "Neovanguardias hipervitalistas en la poesía hispanoamericana (1958-1976): Nihilistas, revolucionarios, solidarios y amorosos". Taller de Letras 52: 11-57.

García-Bedoya, Carlos. 2012. Indagaciones heterogéneas. Estudios sobre literatura y cultura. Lima: Pakarina Editores.

Güich Rodríguez, José. 2006. “Carmen Ollé: La rebelión de los cuerpos”. En Chuecha, Luis Fernando, José Güich Rodríguez y Carlos López Degregori, En la comarca oscura. Lima en la poesía peruana 1950-2000. Lima: Fondo Editorial de la Universidad de Lima. 165-177.

Guillén, Paul. 2006. "Un espejo convexo: Dos imágenes alternas en la poesía peruana de la década del 70 y 80". Galerna 4: 132-144. Recuperado el 11 de abril de 2012, de http:// www.letras.s5.com/pg011206.htm

Masiello, Francine. 2001. El arte de la transición. Buenos Aires: Norma.

Mignolo, Walter. 1986. Teoría del texto e interpretación de textos. México D.F.: Universidad Autónoma de México.

Mora, Tulio. 2009. Hora Zero. Los broches mayores del sonido. Lima: Fondo Editorial Cultura Peruana.

Ollé, Carmen. 1997. Noches de adrenalina / Nights of adrenaline. Edición bilingüe por Anne Archer. Encino: Floricanto Press.

2008. "Prólogo". Antología de la poesía peruana. Fuego abierto. Santiago: LOM. 5-26.

Oviedo, José Miguel. 1973. "Prólogo”. Estos 13. Lima: Mosca Azul Editores. 9-25.

Paz, Octavio. 1990. Los hijos del limo. Barcelona: Seix Barral.

Reisz, Susana. 1996. Voces sexuadas. Género y poesía en Hispanoamérica. Madrid: Universidad de Lleida.

1998. "Escritura femenina y estrategias de representación en la "nueva" poesía peruana". En Kohut, Karl, José Morales Saravia y Sonia V. Rose (Eds.), Literatura peruana hoy. Crisis y creación. Frankfurt: Iberoamericana. 218-233. 